\title{
Nonoperative Management of Venous Ulcers and the Emerging Role of Bioengineered Skin Substitutes
}

EVERETT Y. LAM, M.D., AND GREGORY L. MONETA, M.D.

ABSTRACT Chronic venous ulcers are a common medical problem that have a dramatic medical, economic, and psychosocial impact on patients. Nonoperative therapy has been proven to be effective in controlling the symproms of chronic venous insufficiency and promoting healing of chronic venous leg ulcers. The mainstays of nonoperative treatment continue to be leg elevation and compression therapy. Recently, bioengineered skin substitutes, ranging from an epidermal or dermal layer to a bilayered living skin construct, have been developed to aid in local wound healing and represent an added nonoperative treatment option for venous ulcers.

Keywords Venous ulcer, nonoperative treatment, skin substitutes

Chronic venous leg ulcers are a major and costly medical problem affecting an estimated 600,000 patients in the United States. ${ }^{1}$ In addition, chronic leg ulcers carry significant negative physical, financial, and psychological implications. In a recent quality-of-life study, $65 \%$ of chronic leg ulcer patients had severe pain, $81 \%$ had decreased mobility, and $100 \%$ experienced a negative impact of their disease on their work capacity. ${ }^{2}$ The socioeconomic impact of chronic venous leg ulcers is staggering, with an estimated 2 million workdays lost per year. ${ }^{3}$

E.Y.L., Resident, Division of Vascular Surgery, Oregon Health Sciences University, Portland, OR; G.L.M., Professor of Surgery, Chief, Division of Vascular Surgery, Oregon Health Sciences University, Portland, OR.

Copyright (C) 2000 by Thieme Medical Publishers, Inc., 333 Seventh Avenue, New York, NY 10001, USA

Tel.: +1(212) 584-4662. 0894-8046,p;2000,13,2,69,80,ftx,en; pvs000101 
Nonoperative therapy remains the primary mode of treatment for chronic venous leg ulcers. Although strict bed rest and limb elevation to decrease edema have been known to be effective therapy for venous insufficiency and ulceration, they are impractical as a long-term solution. The goals for therapy are to control symptoms, promote healing of ulcers, and prevent ulcer recurrence while permitting maximal ambulatory status.

Currently, nonoperative compression therapy remains the standard treatment for chronic venous insufficiency and ulceration. Compression therapy can be achieved using a variety of techniques, including elastic compression stockings, paste gauze boots (Unna's boot), multilayer elastic wraps/dressings, and pneumatic compression devices. Over the past decade, bioengineered skin substitutes have been developed for the treatment of chronic leg ulcers. Early reports indicate that the use of a bilayered living skin construct (LSC) combined with compression therapy is an effective treatment for venous ulceration, particularly hard-to-heal ulcers.

\section{COMPRESSION THERAPY}

Currently, the exact mechanism by which compression therapy can improve venous insufficiency remains uncertain. Improvements in skin and subcutaneous tissue microcirculatory hemodynamics as well as a direct effect on subcutaneous pressure have been hypothesized as the mechanisms of compression therapy. ${ }^{4}$ Clinically, routine use of elastic and nonelastic bandages reduces lower extremity edema in patients with chronic venous insufficiency. In addition, supine perimalleolar subcutaneous pressure has been demonstated to be increased with elastic compression. ${ }^{5}$ With edema reduction, cutaneous metabolism may improve due to enhanced diffusion of oxygen and other nutrients to the cellular elements of the skin and subcutaneous tissues. Increases in subcutaneous tissue pressure with elastic compression bandages may counteract transcapillary Starling forces that favor leakage of fluid out of the capillary.

Compression therapy is most commonly achieved with gradient elastic compression stockings. Gradient elastic compression stockings were initially developed by Conrad Jobst in the 1950s. These stockings were made to mimic the gradient hydrostatic forces exerted by water in a swimming pool. Elastic compression stockings are available in various compositions, strengths, and lengths.

The benefits of elastic compression stocking therapy in the treatment of chronic venous insufficiency and ulceration have been documented. ${ }^{6-9}$ In a retrospective study of 113 venous ulcer patients, ${ }^{7}$ Mayberry and colleagues found that the use of below knee 30 to $40 \mathrm{mmHg}$ elastic compression stocking, after first resolving edema and cellulitus if present, resulted in 93\% ulcer healing. Mean time to ulcer healing was 5.3 months. Complete ulcer healing occurred in 99 of 102 patients $(97 \%)$ who were compliant with stocking use versus 6 of 11 patients $(55 \%)$ who were noncompliant $(p<0.0001)$. Longterm follow-up (mean 30 months) was available in 73 patients. Fifty-eight 
patients continued to be compliant with stocking use. Ulcer recurrence in compliant patients was $29 \%$ at 5 years by life table analysis. In noncompliant patients, ulcer recurrence was $100 \%$ at 36 months. Although these results are excellent, other studies indicate that the frequency of venous ulcer healing with compression therapy is often 40 to $50 \%$ at 6 months. ${ }^{10,11}$

Patient compliance with compression therapy is crucial in treating venous leg ulcers. Many patients are often initially intolerant of compression in areas of hypersensitivity adjacent to an active ulcer or at sites of previously healed ulcers. They may also have difficulty applying elastic stockings. To improve compliance, patients should be instructed to wear their stockings only as long as it is easily tolerable and then gradually increase the amount of time stockings are worn. Alternatively, patients can be initially fitted with lesser-strength stockings ( 20 to $30 \mathrm{mmHg}$ ) followed by higher-strength stockings over a period of several weeks. Many commercially available devices, such as silk inner toe liners, stockings with zippered sides, and metal fitting aides, are available to assist patients in applying elastic stockings.

Another method of compression was developed by the German dermatologist Paul Gerson Unna in 1896. Unna's boot has been used for many years to treat venous ulcers and is available in many versions. A typical Unna's boot consists of a three-layer dressing and requires application by trained personnel. A rolled gauze bandage impregnated with calamine, zinc oxide, glycerin, sorbitol, gelatin, and magnesium aluminum silicate is first applied with graded compression from the forefoot to just below the knee. The next layer consists of a 4 -inch-wide continuous gauze dressing followed by an outer layer of elastic wrap also applied with graded compression. The bandage becomes stiff after drying and the rigidity may aid in preventing edema formation. Unna's boot is changed weekly or sooner if the patient experiences significant drainage from the ulcer bed.

Once applied, Unna's boot requires minimal patient involvement and provides contiunous compression and topical therapy. However, the Unna's boot has several disadvantages. It is uncomfortable to wear because of its bulkiness and, thus, may adversely affect patient compliance. In addition, the ulcer cannot be monitored after the boot is applied, the technique is labor intensive, and the degree of compression provided is operator dependent. ${ }^{4}$ Occasionally, contact dermatitis to the constituents of the Unna's boot may require discontinuation of therapy.

The efficacy of Unna's dressing has been examined. In a retrospective 15year review of 998 patients with one or more venous ulcers treated weekly with Unna's dressing, ${ }^{12} 73 \%$ of ulcers healed in patients who returned for more than one treatment. The median time to healing for individual ulcers was 9 weeks. Unna's dressing has been compared to other forms of treatment. A randomized prospective study ${ }^{13}$ comparing Unna's boot to polyurethane foam dressing in 36 patients with venous ulcers demonstrated superior healing over 12 months in the patients treated with Unna's boot (94.7\% versus $41.2 \%)$. 
Additional forms of compression dressing, including multilayered dressings and elastic wraps, have also been used to treat venous ulcers. Multilayered dressings include Profore ${ }^{\circledR}$ (four-layer; Smith and Nephew, London, U.K.), Comprilan ${ }^{\circledR}$ (short stretch; Beiersdorf AG, Charlotte, NC), and SurePress ${ }^{\circledR}$ (long stretch; ConvaTec, Princeton, NJ). The purported advantages of multilayered dressings over gradient elastic compression stockings include maintenance of compression for a longer period of time, more even distribution of compression, and better absorption of wound exudate. However, the effectiveness of these types of compression therapy, like that of Unna's boot, is dependent on the wrapping technique of health care personnel. A commercially available legging orthosis (CircAid ${ }^{\circledR}$ Shaw Therapeutics, Inc.) (Fig. 1), consisting of multiple adjustable Velcro ${ }^{\mathrm{TM}}$-anchored compression bands, provides compression similar to Unna's boot and can be applied daily by the patient. ${ }^{14}$

\section{SKIN SUBSTITUTES}

Over the past decade, significant advances have been made in the development of skin substitutes designed to aid in achieving permanent closure of open wounds, including venous ulcers. The ideal skin substitute should provide rapid wound coverage and simultaneously act as a barrier against

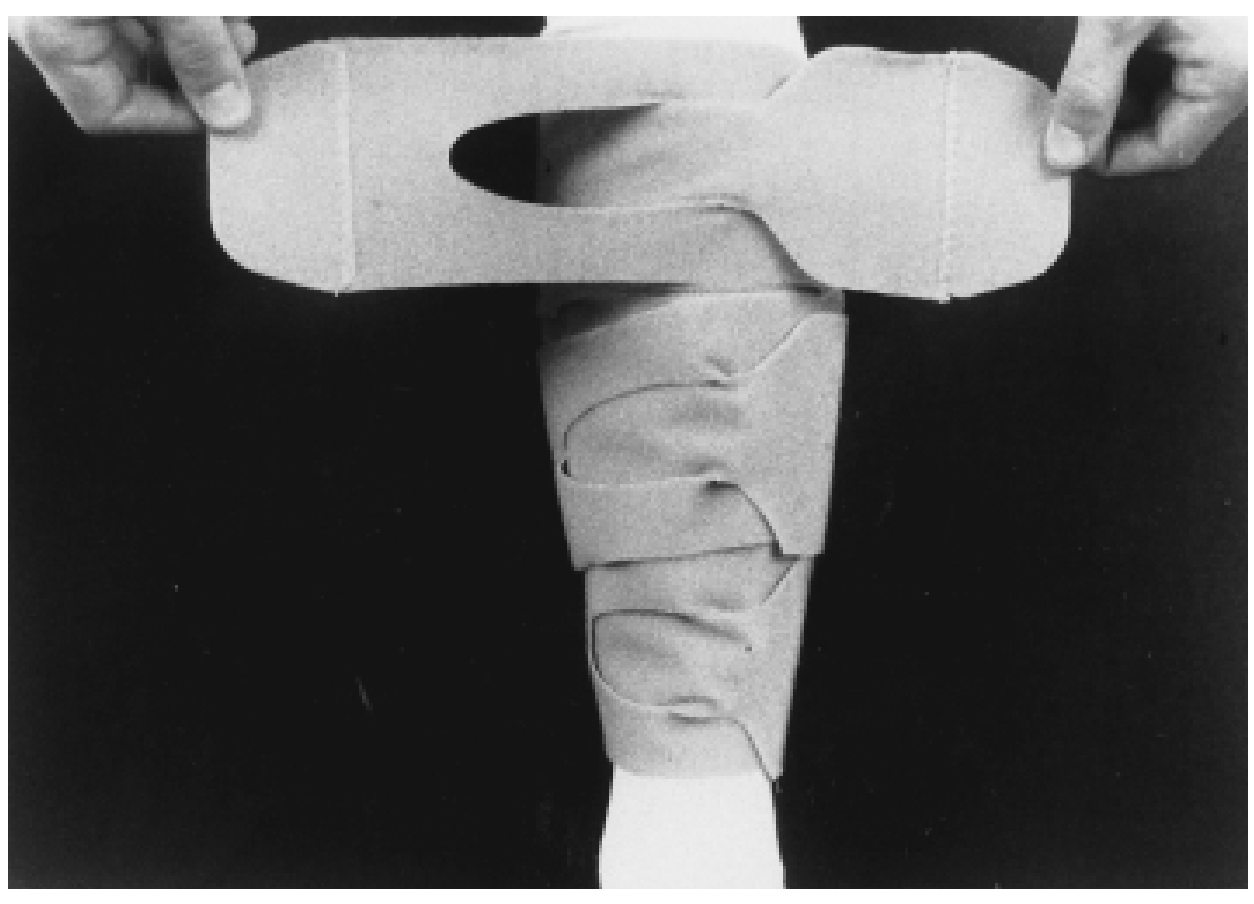

Fig. 1 A commercially available legging orthosis used for compression therapy (CircAid®). 
microorganisms and fluid loss. In addition, it should resist mechanical pressures and produce long-term stability with minimal contraction and scarring. For widespread clinical applicability, the skin substitute should be safe, costeffective, and easy to apply and store.

Several types of skin substitutes are commercially available or under clinical study in the United States. ${ }^{3}$ Bioengineered skin ranges in composition from acelluar skin substitutes to partial living skin substitutes. They may consist of acellular collagen frameworks, epidermal or dermal layers, or complete, bilayered LSCs with allogeneic dermis and epidermis.

Two types of acellular skin substitutes are available: AlloDerm ${ }^{\circledR}$ (LifeCell Corporation, Branchburg, NJ) and Biobrane ${ }^{\circledR}$ (Dow Hickam, Morgantown, WV). AlloDerm ${ }^{\circledR}$ is derived from cadaveric skin and is composed of a collagenous dermal matrix. ${ }^{15}$ The epiderimis and dermal fibroblasts are removed from the intact skin, and the remaining collagen material is freeze-dried. At the time of application, AlloDerm ${ }^{\circledR}$ is reconstituted with saline, placed on the wound, and then covered with an epidermal autograft. Biobrane ${ }^{\circledR}$ consists of a nylon mesh coated with porcine type I collagen layered onto a silicone film. ${ }^{16}$ The Biobrane ${ }^{\circledR}$ graft is applied to the wound, the silicone film is then removed, and the collagen mesh is left to cover the wound.

Two types of partial living skin substitutes are in clinical development. Epicel $^{\mathrm{TM}}$ (Genzyme Tissue Repair, Cambridge, MA) is a single-layer epidermal autograft that is prepared from a small $(2 \mathrm{~cm} \times 2 \mathrm{~cm})$ patch of skin removed from the patient. The keratinocytes are cultured over 2 weeks to form sheets of epidermis as large as $2 \mathrm{~m}^{2}$. This type of skin substitute does not contain a dermal layer and thus cannot limit wound contraction or improve wound durability. ${ }^{17}$ Dermagraft ${ }^{\mathrm{TM}}$ (Advanced Tissue Sciences, LaJolla, CA/Smith and Nephew, London, UK) consists of human fibroblasts grown to a confluent single-layer tissue in a polyglycolic or polyglactin matrix. ${ }^{17}$ Dermagraft ${ }^{\mathrm{TM}}$ has been used in the treatment of diabetic foot ulcers. ${ }^{18,19}$ Dermagraft-Temporary Covering ${ }^{\mathrm{TM}}$ (Advanced Tissue Sciences/Smith and Nephew) is an acellular version of Dermagraft ${ }^{\mathrm{TM}}$ with a silicone surface bonded to a nylon mesh containing the devitalized fibroblasts and their matrix products. This product has been approved for use as a temporary covering in the treatment of severe, life-threatening burns.

Integra $^{\mathrm{TM}}$ Artificial Skin-Dermal Regeneration Template ${ }^{\mathrm{TM}}$ (Integra LifeSciences Corporation) is a noncellular skin substitute consisting of a dermal layer and an epidermal layer. ${ }^{17}$ The dermal layer is made of a porous matrix of bovine tendon collagen and chondroitin-6-sulfate. The epidermal layer is made of a thin silicone layer that is removed several weeks after grafting and replaced with a thin sheet of autologous skin. ${ }^{17}$ This type of artificial skin construct has been used to treat severe burn injuries. ${ }^{20}$

Apligraf ${ }^{\mathrm{TM}}$ (Organogenesis Inc./Novartis Pharmaceuticals Corporation, East Hanover, NJ) (Fig. 2) is a bilayered LSC that closely approximates human skin. It contains a protective stratum corneum and a keratinocyte- 


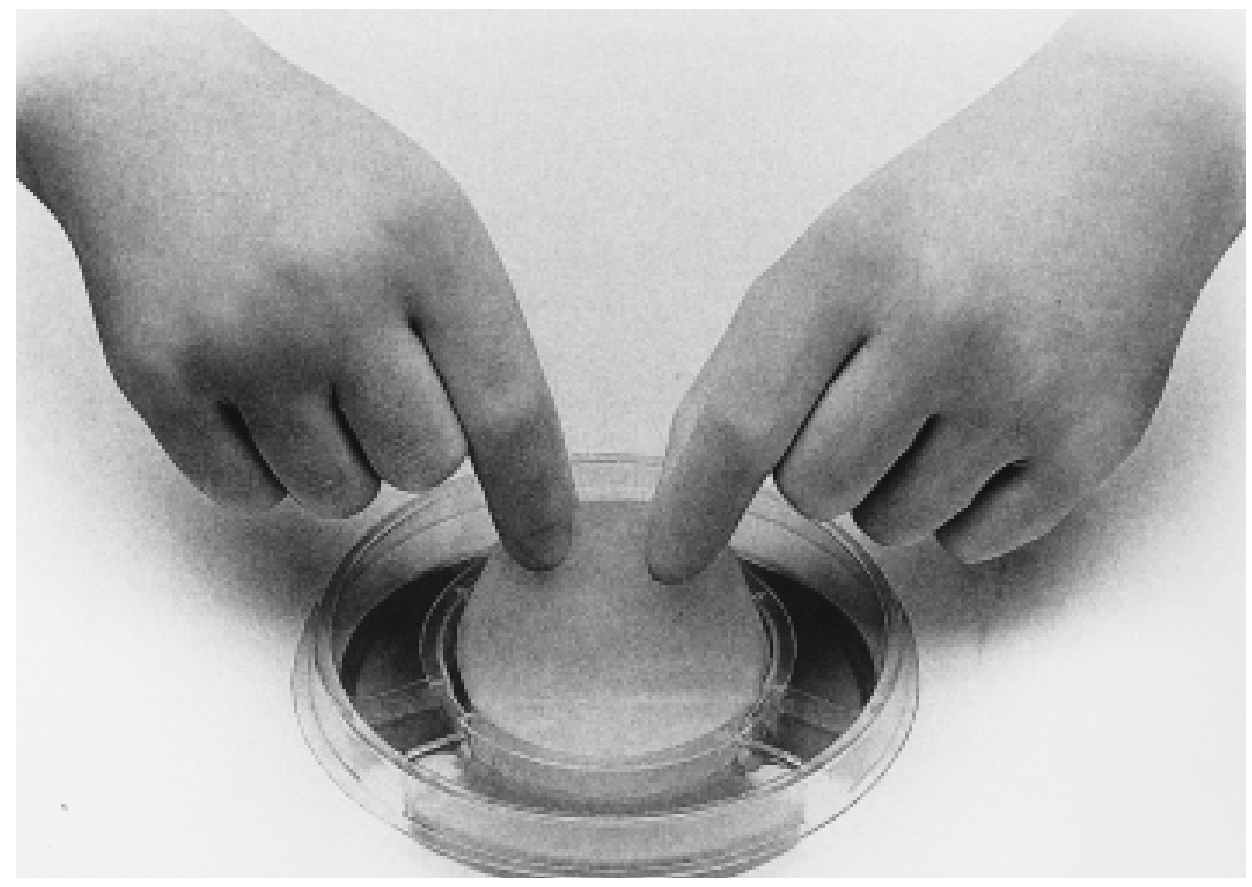

Fig. 2 Gross appearance of living skin construct (Apligraf ${ }^{\mathrm{TM}}$ ) in a container containing agarose gel nutrient medium to maintain cell viability. (From Skin Substitute Consensus Development Panel. Vasc Surg 1999;33:197-210. Used with permission.)

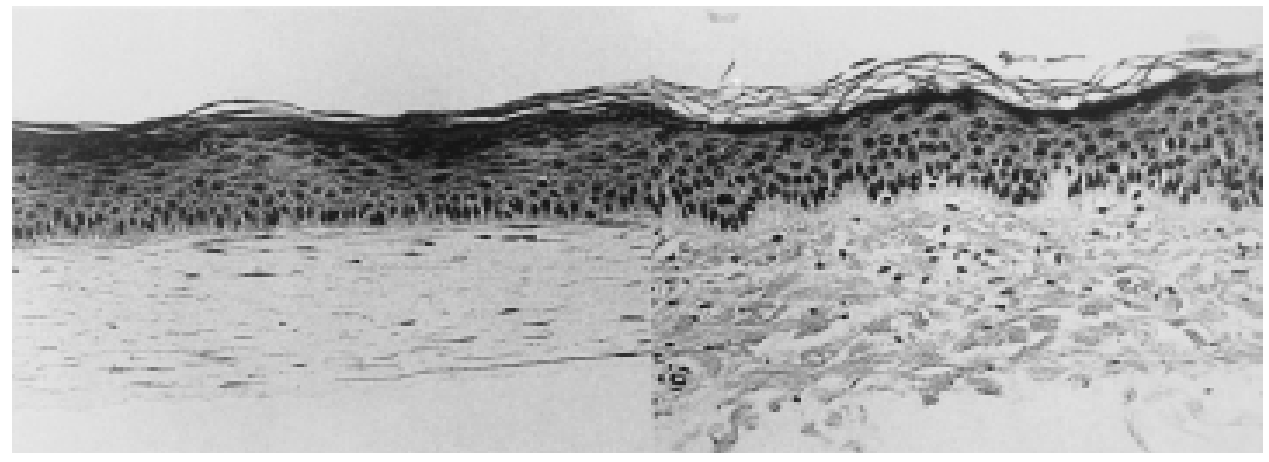

Fig. 3 Photomicrographs of hematoxylin-eosin-stained cross-sections of Apligraf ${ }^{\mathrm{TM}}$ (left) and human skin (right). Note that the living skin construct has a thick epidermis with well-developed spinous, suprabasal, and basal layers below the mature stratum corneum. (From Skin Substitute Consensus Development Panel. Vasc Surg 1999;33:197-210. Used with permission.) 
containing epidermis overlying a dermis consisting of dermal fibroblasts in a collagen matrix. ${ }^{21}$ The keratinocytes and fibroblasts are derived from newborn foreskin. The metabollically active fibroblasts associate with and organize the bovine collagen matrix in the dermal layer. At the dermal-epidermal junction, a protobasement membrane is present that contains laminin, type IV collagen, and kalinin. The epidermis contains a basal layer with a mitotic rate similar to that of human skin. The suprabasal epidermis has spinous and granular layers with a covering of stratum corneum $^{3}$ (Fig. 3).

Apligraf ${ }^{\mathrm{TM}}$ is supplied as a disk of living tissue within an aseptic polyethylene pouch containing an agarose gel nutrient medium. The LSC is delivered live and must be used within 5 days of its release from the manufacturer. ${ }^{21}$ The thickness of Apligraf ${ }^{\mathrm{TM}}$ is similar to a full-thickness skin graft and ranges from 0.5 to $1.0 \mathrm{~mm}$. It is easily handled and applied and readily conforms to irregularly contoured ulcer beds.

The efficacy of Apligraf ${ }^{\mathrm{TM}}$ in the treatment of venous ulcers has been examined in a prospective, randomized study comparing multilayer compression therapy alone to treatment with Apligraf ${ }^{\mathrm{TM}}$ in addition to multilayered compression therapy. ${ }^{10}$ Significantly more patients treated with Apligraf ${ }^{\mathrm{TM}}$ had healed ulcers at 6 months $(63$ vs. $49 \%, p=0.02)$. Median time to complete ulcer closure was significantly shorter in patients treated with Apligraf ${ }^{\mathrm{TM}}$ than in those treated with multilayered compression therapy alone (61 days vs. 181 days, $p=0.003$ ). The ulcers that showed the greatest benefit with LSC treatment were large and deep $\left(>1000 \mathrm{~mm}^{2}\right)$ or were longstanding $(>6$ months). No evidence of rejection or sensitization has been noted in response to Apligraf ${ }^{T M}$ application.

\section{VENOUS ULCER MANAGEMENT}

The proper management of chronic venous ulcers involves both medical expertise and patient compliance. Patients must be effectively educated about their chronic disease and the need to follow treatment recommendations to heal current ulcers and prevent recurrence. A definitive diagnosis of venous ulceration must be made prior to undergoing treatment. A full history should be obtained from a patient presenting with lower-extremity ulcerations, including medications and associated medical conditions that may promote lower-extremity ulceration. Arterial insufficiency is assessed by physical examination or noninvasive studies. In addition, systemic conditions that affect wound healing, such as diabetes mellitus, immunosuppression, or malnutrition, should be treated as much as possible.

In our clinic currently, the treatment of venous ulcers begins with localized care of the ulcer. In patients with severe edema, bedrest and limb elevation are initially prescribed to aid in edema resolution. Necrotic or fibrinous material is debrided as tolerated. Cellulitis is treated with short-term intravenous or oral antibiotics. Local wound care consists of soap and water scrubbings 
followed by dry gauze changed every 12 hours. No topical agents are applied directly to the ulcer, but $0.1 \%$ hydrocortisone cream is applied every 12 hours to surrounding areas of stasis dermatitis.

Once edema and cellulitis are adequately treated and the ulcer bed is clean, compression therapy is initiated. Our preference is compression elastic stockings. When compression stockings are used, patients are fitted with belowknee 30 to $40 \mathrm{mmHg}$ elastic compression stockings. (Multilayered wraps, Unna's boot, and the CircAid ${ }^{\circledR}$ legging orthosis are also used in our clinic depending on the clinical situation.) Instructions are given for the stockings to be worn at all times while ambulatory and removed on going to bed. Wound care throughout the course of compression therapy is essential and consists of daily soap and water washings of the ulcer. The ulcer is covered with a dry gauze and held in place by the compression stocking. Compression stockings are replaced every 3 to 6 months to maintain adequate elastic strength.

If exudate is a particular problem or if the patient has difficulty applying elastic compression stockings, we employ multilayer wrapping for the initial management of venous ulcers. Multilayered wraps are changed weekly or more often by trained medical personnel depending on the amount of wound exudate. In some patients with very large legs, the $\operatorname{CircAid}^{\circledR}$ device is used with satisfactory anecdoctal results.

At a minimum of 4 weeks of compression therapy, the venous ulcer is assessed for progress in healing. Compression therapy is continued if the ulcer appears to be healing. If no or minimal healing progress has been achieved, application of LSC can be considered (Fig. 4). Prior to application of a LSC, the venous ulcer should be clean and exudate free. There should be no evidence of purulence or celluliltis. The LSC is cut to overlap the wound edges slightly and is covered and kept moist with a nonadherent primary dressing. The LSC can be fenestrated to provide improved wound drainage. It is held in place by a foam or folded gauze pressure bolster secured with adhesive tape. We have not found stapling or suturing the graft to be necessary. Finally, compression therapy is applied.

The first dressing change is performed approximately 3 to 5 days after LSC application. Whether or not the entire dressing should be stripped down to the wound to assess the status of the graft or just to the interface dressing is based on physician discretion. A second dressing change, including the interface dressing, is performed at 7 to 10 days postgrafting. Initial dressings following application of the LSC may be malodorous and saturated with a blue-green exudate. This does not necessarily indicate loss of the graft, and the graft should not be removed. Over the ensuing weeks, the exudate decreases.

The decision to reapply LSC is based on the response of the ulcer to the first graft at a minimum of 3 to 6 weeks (Fig. 5). If the ulcer has shown significant healing at this point, compression therapy alone should be contin- 

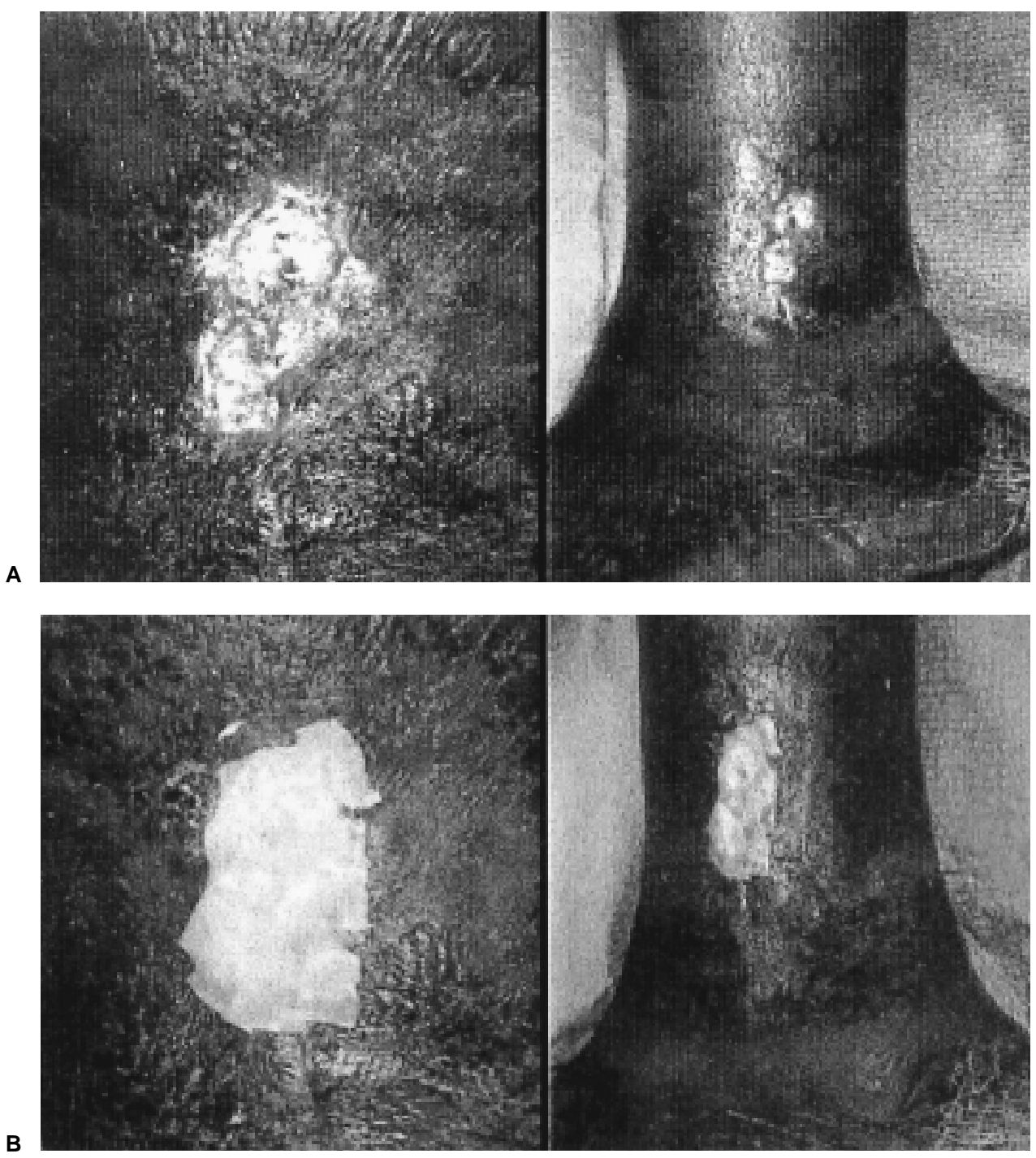

Fig. 4 Placement of Apligraf ${ }^{\mathrm{TM}}$. (A) Appearance of venous stasis ulcer prior to application of Apligraf ${ }^{\mathrm{TM}}$ (B) Postplacement of Apligraf ${ }^{\mathrm{TM}}$. Note that the Apligraf ${ }^{\mathrm{TM}}$ is placed over the wound and can be secured with either a foam or gauze bolster under a compression bandage. 

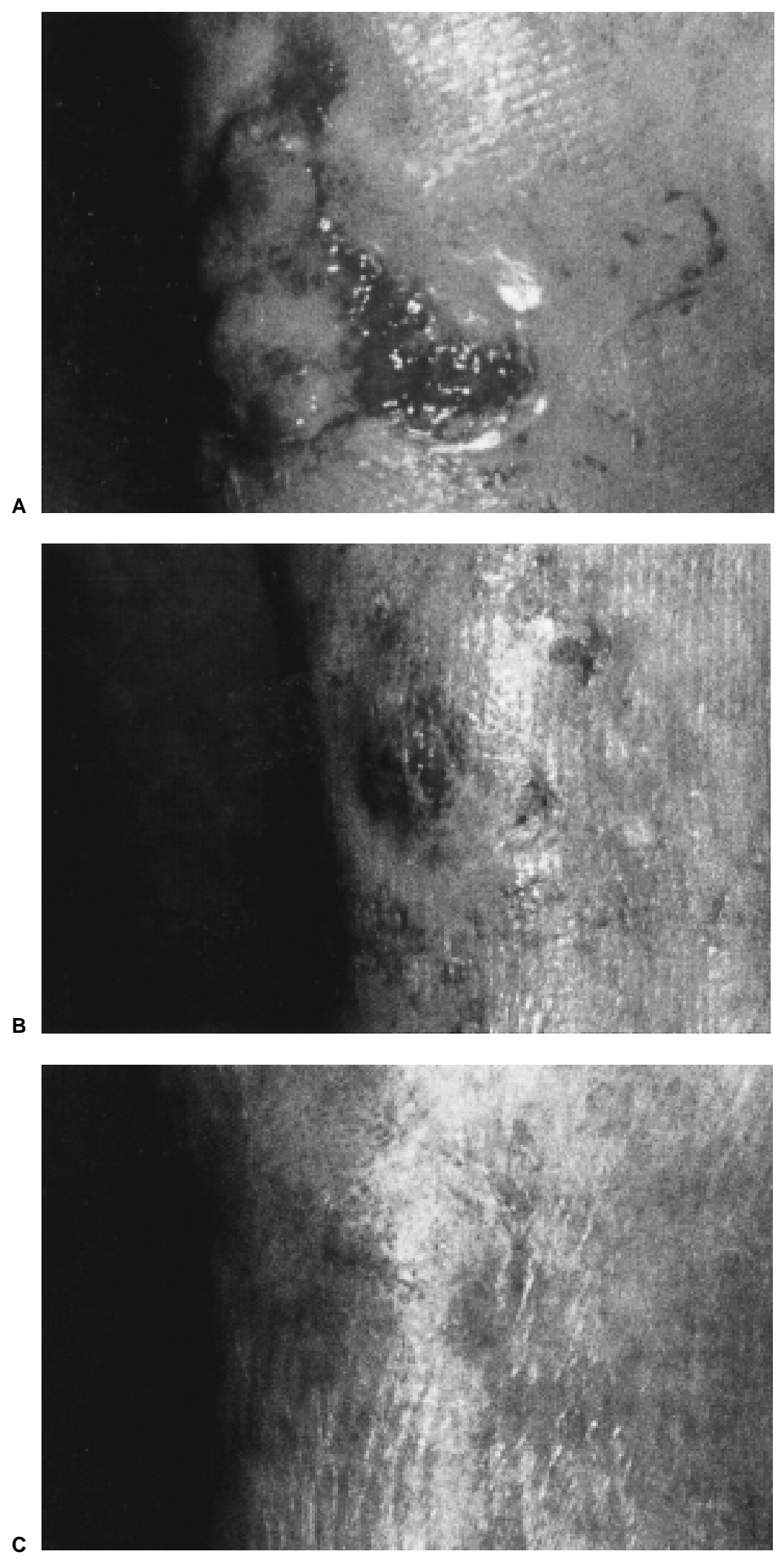

Fig. 5 Appearance of venous stasis ulcer after placement of Apligraf ${ }^{\mathrm{M}}$. (A) Three weeks after Apligraf ${ }^{T M}$ placement. Note the peripheral granulation tissue and the exudate overlying the wound bed. (B) Nine weeks after Apligraf $^{\text {TM }}$ placement. The wound is nearly healed. (C) Thirteen weeks after Apligraf ${ }^{\mathrm{M}}$ placement. The wound is fully healed. 


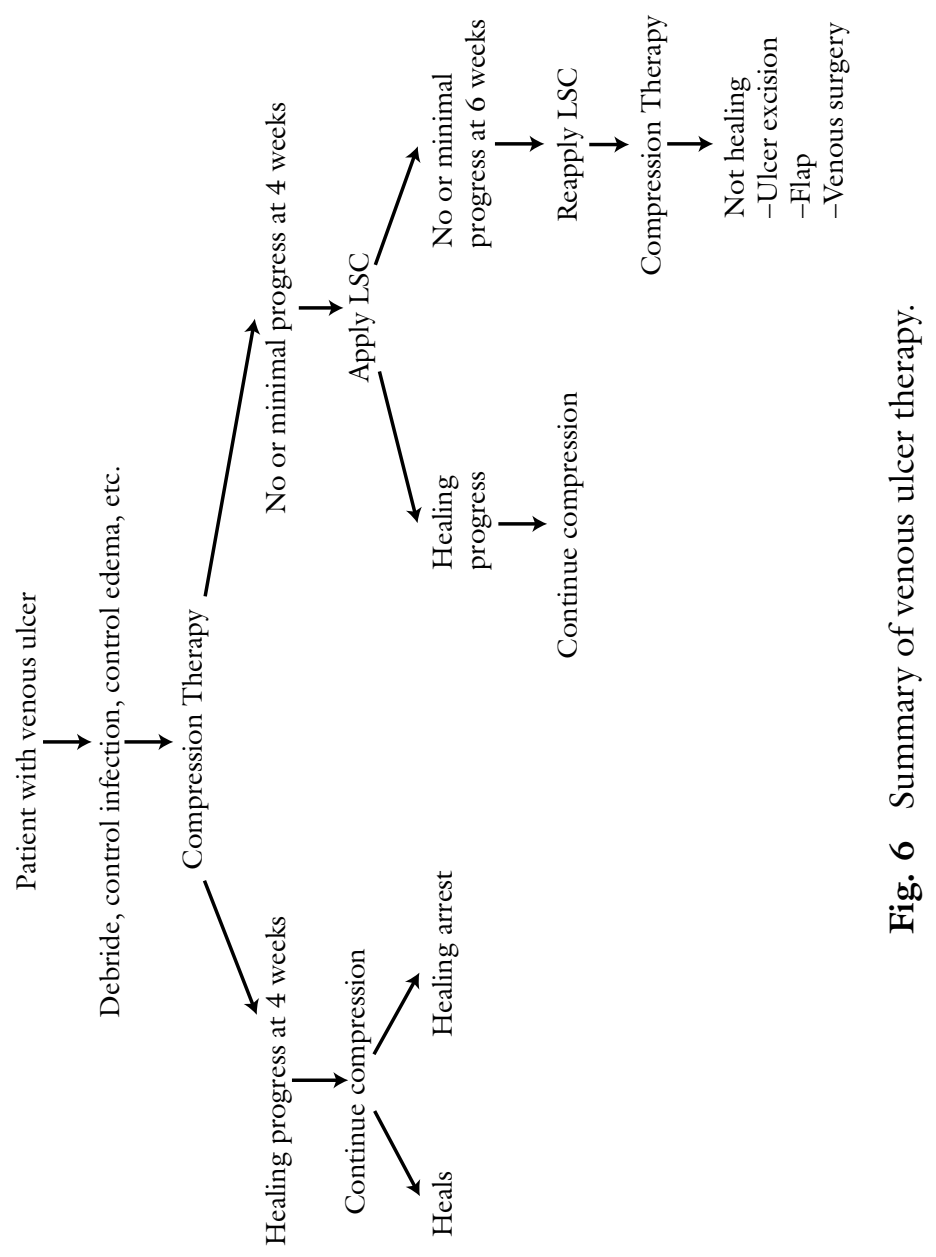


ued. Reapplication of LSC should be considered if the ulcer remains large and there is no evidence of infection. If the ulcer worsens or remains static after two applications of LSC, the patient should be reassessed to determine if another component of treatment needs to be changed or added (Fig. 6). There appears to be little benefit in a third or more application of a LSC.

Close follow-up of patients with venous insufficieny is essential. At each visit, patient education is emphasized. Patients should be instructed to avoid prolonged periods of standing, to initiate and maintain a regimen of proper skin care, and to use compression stockings indefinitely. The adequacy of edema control is rountinely assessed and the degree of compression adjusted accordingly.

\section{CONCLUSION}

Venous ulcer management is challenging and requires continual patient and physician involvement. Patient education is essential to maintain compliance with treatment. Compression achieved with a variety of elastic, rigid, and multilayered dressings and wound care remain the primary nonoperative therapies of venous ulcers. Newly available skin substitutes have increased the options available to treat venous ulcers, particularly large and difficult-to-heal ulcers.

\section{REFERENCES}

1. Falanga V. Venous ulceration. J Dermatol Surg Oncol 1993;19:764-771

2. Phillips T, Stanton B, Provan A, Lew R. A study of the impact of leg ulcers on quality of life: financial, social, and psychologic implications. J Am Acad Dermatol 1994;31:49-53

3. Skin Substitute Consensus Development Panel. Nonoperative management of venous leg ilcers: evolving role of skin substitutes. Vasc Surg 1999;33:197-210

4. Nehler MR, Moneta GL, Porter JM. The lower extremity venous system. Part II: the pathophysiology of chronic venous insufficiency. Perspect Vasc Surg 1992;5:81-97

5. Nehler MR, Moneta GL, Woodard DM, et al. Perimalleolar subcutaneous tissue pressure effects of elastic compression stockings. J Vasc Surg 1993;18:783-788

6. Dinn E, Henry M. Treatment of venous ulceration by injection sclerotherapy and compression hosiery: a 5-year study. Phlebology 1992;7:23-26

7. Mayberry JC, Moneta GL, Taylor LM, Jr., Porter JM. Fifteen-year results of ambulatory compression therapy for chronic venous ulcers. Surgery 1991;109:575-581

8. Kitahama A, Elliott LF, Kerstein MD, Menendez CV. Leg ulcer. Conservative management or surgical treatment? JAMA 1982;247:197-199

9. Anning ST. Leg ulcers—-the results of treatment. Angiology 1956;7:505-517

10. Falanga V, Margolis D, Alvarez O, et al. Rapid healing of venous ulcers and lack of clinical rejection with an allogeneic cultured human skin equivalent. Human Skin Equivalent Investigators Group [see comments]. Arch Dermatol 1998;134:293-300

11. Phillips TJ. New skin for old: developments in biological skin substitutes [editorial; comment]. Arch Dermatol 1998;134:344-349

12. Lippmann HI, Fishman LM, Farrar RH, Bernstein RK, Zybert PA. Edema control in the mangement of disabling chronic venous insufficiency. Arch Phys Med Rehabil 1994; 75:436-441 
13. Rubin JR, Alexander J, Plecha EJ, Marman C. Unna's boot vs polyurethane foam dressings for the treatment of venous ulceration. A randomized prospective study. Arch Surg $1990 ; 125: 489-490$

14. Vernick SH, Shapiro D, Shaw FD. Legging orthosis for venous and lymphatic insufficiency. Arch Phys Med Rehabil 1987;68:459-461

15. Wainwright D, Madden M, Luterman A, et al. Clinical evaluation of an acellular allograft dermal matrix in full-thickness burns. J Burn Care Rehabil 1996;17:124-136

16. McHugh TP, Robson MC, Heggers JP, et al. Therapeutic efficacy of Biobrane in partialand full-thickness thermal injury. Surgery 1986;100:661-664

17. Cairns BA, deSerres S, Peterson HD, Meyer AA. Skin replacements. The biotechnological quest for optimal wound closure. Arch Surg 1993;128:1246-1252

18. Naughton G, Mansbridge J, Gentzkow G. A metabolically active human dermal replacement for the treatment of diabetic foot ulcers. Artif Organs 1997;21:1203-1210

19. Gentzkow GD, Iwasaki SD, Hershon KS, et al. Use of dermagraft, a cultured human dermis, to treat diabetic foot ulcers [see comments]. Diabetes Care 1996;19:350-354

20. Heimbach D, Luterman A, Burke J, et al. Artificial dermis for major burns. A multicenter randomized clinical trial. Ann Surg 1988;208:313-320

21. Sibbald RG. Apligraf living skin equivalent for healing venous and chronic wounds. J Cutan Med Surg 1998;3(Suppl 1):24-28 
Selection of this manuscript for publication in Perspectives is very timely, as there are many new techniques advocated for the closure of chronic wounds. Venous ulcers in particular are targets for treatment by vascular surgeons.

There are two strengths to the present presentation. The first is a complete discussion of the value of compression therapy in treating venous ulceration. All interested physicians agree that compression therapy is essential in treating the complications of chronic venous insufficiency. In particular, this reviewer found the discussion of the non-stretch dressing, including Unna's boot, to be interesting. Clearly, the non-stretch characteristic allows comfort for the patient during recumbency when virtually no pressure is applied and yet provides effective compression proportional to the degree of vascular insufficiency when the patient and the limb are in the vertical position. ${ }^{1}$ It may be that the multilayered dressings referred to by Drs. Lam and Moneta are actually virtually non-stretch, and, therefore, more effective than elastic stockings.

The second strength of this presentation is the complete description of skin substitutes. Several of these have been the subject of maximal advertising and personal detailing. The experience of the Oregon group in utilizing skin substitutes is interesting and informative. In the case illustrated, one might question why autogenous skin was not used rather than the Apligraf, as the wound did not appear to be particularly difficult to manage using historically proven techniques of wound coverage.

The title of this presentation includes the phrase nonoperative management but it would be remiss not to mention the fact that operations are clearly an adjunct to treatment of venous leg ulcer. Simple healing of the ulcer should not be the most desirable endpoint. Instead the goals for therapy should be as stated in the introduction, "To control symptoms, promote healing of ulcers, and prevent ulcer recurrence." Operative intervention need not be complex. In the Leicester study published last year, median time to venous ulcer healing was 18 weeks. ${ }^{2}$ Only superficial venous surgery was done and no patients were treated with external compression or skin grafting.

Failures of superficial surgery have been encountered. In the study from Ulm, ${ }^{3}$ venous ulcers that had been active for a median of 12 years, healed in 9 of 16 cases within 14 to 50 days after addition of subfascial endoscopic perforator vein surgery to the previously performed vein stripping. Kolvenbach ${ }^{4}$

J.J.B., Professor of Surgery, University of California, San Diego; Clinical Professor of Surgery, Uniformed Services University of the Health Sciences, Bethesda, MD.

Copyright (c) 2000 by Thieme Medical Publishers, Inc., 333 Seventh Avenue, New York, NY 10001, USA.

Tel.: +1(212) 584-4662. 0894-8046,p;2000,13,2,83,84,ftx,en; pvs00101A 
in Dusseldorf has shown that inadequate superficial surgery and poorly done perforator vein surgery can be corrected by redoing the perforator vein surgery. These references are indicators of the importance of attending to superficial reflux and perforator outflow in patients with leg ulcer. Having said that there are patients who do not fare well with either conservative care or operative intervention. These are patients with previous deep venous thrombosis, popliteal vein reflux, ${ }^{5}$ and patients with superficial venous surgery and perforator interruption who are not treated by elastic compression. ${ }^{6}$

\section{REFERENCES}

1. Bergan JJ, Sparks SR. Nonelastic compression: an alternative in management of chronic venous insufficiency. J WOCN 2000;27:83-89

2. Bello M, Scriven M, Harthorne T, Bell PR, Naylor AR, London NJ. Role of superficial venous surgery in the treatment of venous ulceration. Br J Surg 1999;86:755-759

3. Proebstle TM, Weisel G, Paepcke U, Gass S, Weber L. Light reflection rheography and clinical course of patients with advanced venous disease before and after endoscopic subfascial division of perforating veins. Dermatol Surg 1998;24:771-776

4. Kolvenbach R, Ramadan H, Schwierz E. Redone endoscopic perforator surgery: feasibility and failure analysis. J Vasc Surg 1999;30:720-726

5. Brittenden J, Bradbury AW, Allan PL, Prescott RJ, Harper DR, Ruckley CV. Popliteal vein reflux reduces the healing of chronic venous insufficiency. Br J Surg 1998;85:60-62

6. Scriven JM, Bianchi V, Hartshorne T, Bell PRF, Naylor AR, London NJM. A clinical and hemodynamic investigation into the role of calf perforating vein surgery in patients with venous ulceration and deep venous incompetence. Eur J Vasc Endovasc Surg 1998;16: $148-152$

\footnotetext{
**The Last Word on this article can be found on p. 127.
} 